\title{
Evaluation of phenylcyclopropylamine compounds by enzymatic assay of lysine-specific demethylase 2 in the presence of NPAC peptide
}

\author{
Taeko Kakizawa, ${ }^{\mathrm{a}}$ Tamio Mizukami, ${ }^{\mathrm{b}}$ Yukihiro Itoh, ${ }^{\mathrm{c}}$ Makoto Hasegawa, ${ }^{\mathrm{b}}$ Ryuzo \\ Sasaki ${ }^{\mathrm{b}}$ and Takayoshi Suzuki ${ }^{\mathrm{c}, *}$ \\ ${ }^{a}$ Department of Chemistry and Biochemistry, School of Advanced Science and Engineering, Waseda University, Shinjuku, \\ Tokyo 169-8555, Japan \\ ${ }^{b}$ Graduate School of Bio-Science, Nagahama Institute of Bio-Science Technology, 1226 Tamura-cho, Nagahama, Shiga 526- \\ 0829, Japan \\ ${ }^{c}$ Graduate School of Medical Science, Kyoto Prefectural University of Medicine, 1-5 Shimogamohangi-cho, Sakyo-ku, Kyoto \\ 606-0823, Japan
}

Keywords: inhibitor; lysine-specific demethylases 1 and 2 (LSD1 and LSD2); NPAC peptide; histone H3K4 demethylation *Corresponding author. Tel and fax: +81-75-703-4937; e-mail: suzukit@koto.kpu-m.ac.jp

\begin{abstract}
Lysine-specific demethylase 2 (LSD2) demethylates mono- and dimethylated Lys-4 of histone H3 (H3K4me1 and $\mathrm{H} 3 \mathrm{~K} 4 \mathrm{me} 2)$. NPAC protein is known to interact with LSD2 and promote its H3K4 demethylase activity. In this study, we established a demethylation assay system that utilizes recombinant LSD2 in the presence of a synthetic NPAC peptide. Several phenylcyclopropylamine (PCPA)-based inhibitors were examined for their LSD2 inhibitory activity in the LSD2 enzymatic assay with the NPAC peptide. The assay results showed that the PCPA derivatives, including NCD41, selectively inhibited LSD1 in preference to LSD2.
\end{abstract}

Lysine-specific demethylase 1 (LSD1) and LSD2 are flavin adenine dinucleotide (FAD)-dependent LSD family proteins that demethylate mono- and dimethylated Lys-4 of histone $\mathrm{H} 3$ (H3K4me1 and $\mathrm{H} 3 \mathrm{~K} 4 \mathrm{me} 2) .{ }^{1}$ As LSD1 is an important target in cancer therapy, many groups have pursued the development of LSD1 inhibitors. ${ }^{2}$ A majority of the previously reported LSD1 inhibitors are the derivatives of phenylcyclopropylamine (PCPA) (Figure 1). PCPA per se is known to inhibit several flavin-dependent enzymes, such as LSD1 and monoamine oxidases (MAOs), by forming the FAD-PCPA adduct through the reaction with FAD in the active site of the enzyme (Figure 2). ${ }^{2}$ We have identified PCPA-based LSD1 inhibitors, such as NCL1 ${ }^{3,4}$ and the NCD series of compounds ${ }^{5,6}$ (Figure 1) that efficiently inhibit LSD1 in preference to MAOs. However, the LSD2 inhibitory activities of NCL1 and NCDs have not yet been tested due to the weak demethylase activity of recombinant LSD2. Thus, we
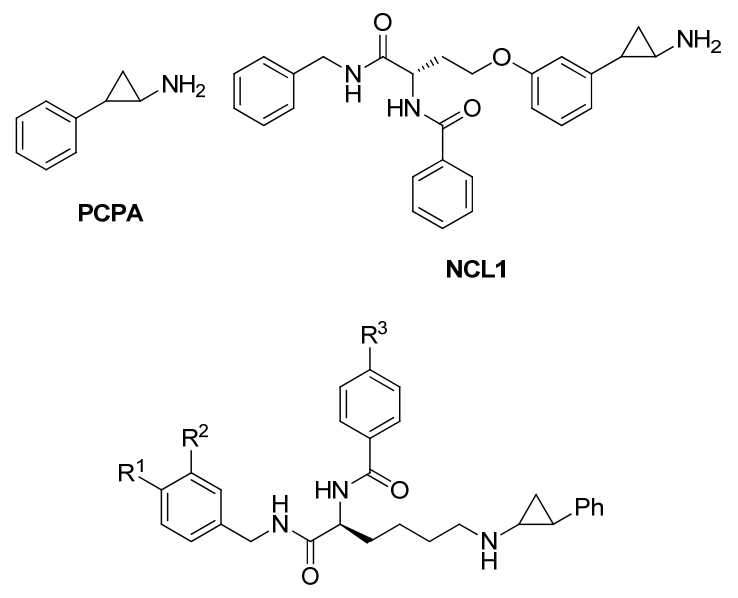

NCD18: $R^{1}=R^{2}=R^{3}=H$ NCD25: $R^{1}=R^{2}=H, R^{3}=P h$ NCD33: $\mathbf{R}^{1}=\mathrm{Cl}, \mathbf{R}^{2}=\mathrm{H}, \mathbf{R}^{3}=\mathrm{Ph}$ NCD41: $R^{1}=H, R^{2}=C F_{3}, R^{3}=P h$

Figure 1 Chemical structures of PCPA, NCL1, NCD18, NCD25, NCD33, and NCD41. 


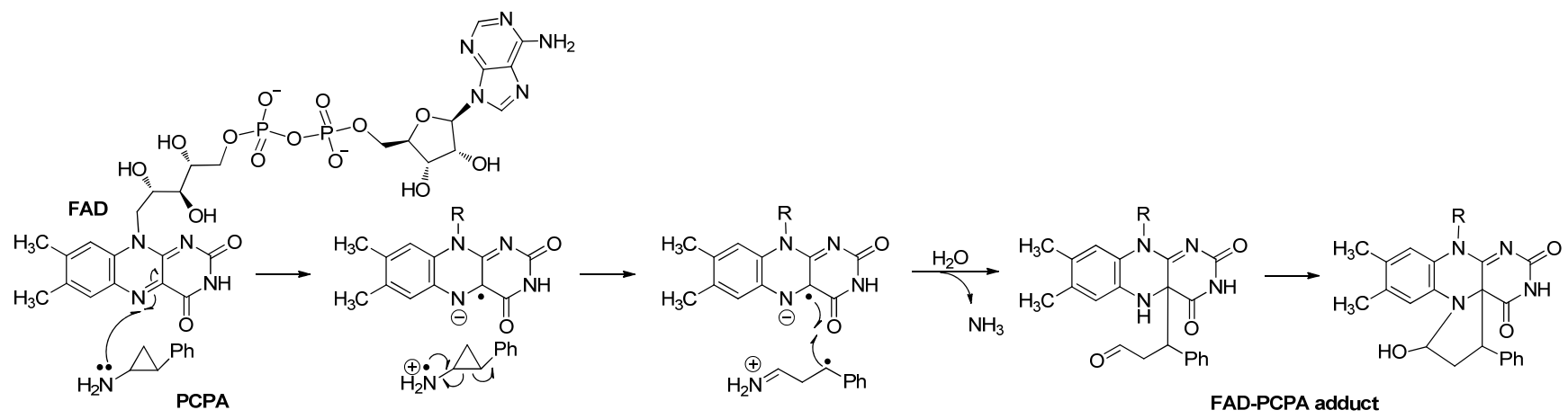

Figure 2. Proposed mechanism of flavin-dependent enzyme inhibition by PCPA.

have been interested in the LSD2-inhibitory activity of the inhibitors. Recently, Yang et al. disclosed that LSD2 possesses unexpected E3 ubiquitin ligase activity and inhibits lung cancer cell growth by promoting the ubiquitylation and degradation of $\mathrm{O}$-linked $\mathrm{N}$ acetylglucosamine transferase (OGT), and indicated that the inhibition of LSD2 may disrupt these pathways. ${ }^{7}$ They also suggested that LSD1 inhibitors that do not affect LSD2 activity may be effective as anticancer agents. We report herein the establishment of an LSD2 assay system by using a peptide and the evaluation of the LSD2 inhibitory activity of PCPA-based inhibitors, which led to the identification of selective inhibitors for LSD1 over LSD2.

Initially, we tried to conduct a mass-spectrometry-based in vitro enzymatic assay using recombinant $\operatorname{LSD} 2^{8}$ to evaluate the inhibitory activity of several LSD1 inhibitors. However, the demethylase activity of recombinant LSD2 was so weak that we could not accurately evaluate the LSD2 inhibitory activity of the PCPA derivatives. Thus, further investigations were needed to establish an LSD2 enzyme assay system that would enable us to accurately evaluate the LSD2 inhibitory activity of our inhibitors.

Fang et al. characterized NPAC protein (also known as GLYR1) as an LSD2-specific cofactor that facilitates LSD2-mediated H3K4me1 and H3K4me2 demethylation. $^{9}$ They also determined the crystal structures of LSD2 alone and LSD2 in complex with the NPAC protein in the absence and presence of a histone H3 peptide. The structures revealed that the NPAC protein stabilizes the interaction between LSD2 and the histone $\mathrm{H} 3$ peptide, and thus enhances the enzymatic activity of LSD2. ${ }^{10}$ Based on these reports, we synthesized an NPAC peptide and attempted to perform a demethylation assay with recombinant LSD2 to confirm that the demethylation activity of LSD2 is enhanced in the presence of the NPAC peptide. First, the dodecapeptide of NPAC (residues 214-225) was produced as a wild-type (WT) sequence of $\mathrm{H}_{2} \mathrm{~N}$ DPHFHHFLLSQT-OH (Figure 3 ) by standard solidphase peptide synthesis using the Fmoc strategy. ${ }^{11,12}$ Its mutant (MT) peptide $\mathrm{H}_{2} \mathrm{~N}$-DPHAHHFLLSQT-OH (Figure 3) was also prepared as a negative control whose cofactor activity has been reported to be lower than that of WT NPAC. ${ }^{9}$ Next, to confirm the enhanced activity of LSD2, the histone demethylation assay was carried out in $20 \mu \mathrm{L}$ of $50 \mathrm{mM}$ HEPES-NaOH (pH 8.5) containing $0.1 \%$ BSA buffered solution at $37{ }^{\circ} \mathrm{C}$ for $1 \mathrm{~h}$ with $10 \mu \mathrm{M} \mathrm{H} 3 \mathrm{~K} 4 \mathrm{me} 2$ substrate peptide that bears a dimethylated lysine at position 4 of a 21 -amino-acid LSD1 substrate peptide, in the absence or presence of $0.5 \mu \mathrm{g}$ of recombinant LSD2 and $0.5 \mu \mathrm{g}$ of NPAC peptide. ${ }^{13}$ Demethylation efficiency was estimated by matrix-assisted laser desorption ionization time-of-flight mass spectrometry (MALDI-TOF MS) on the basis of the peak intensities of the products (Figure 4). The analysis of the substrate and demethylated product peptides is summarized in Figure 5. Compared with the three controls (Figure 5, entries 1 to 3 ), in the LSD2NPAC system, LSD2 efficiently removed a methyl group from its substrate $\mathrm{H} 3 \mathrm{~K} 4 \mathrm{me} 2$ to give $\mathrm{H} 3 \mathrm{~K} 4 \mathrm{me} 1$ as the major product (Figure 5, entry 4). Interestingly, the addition of MT NPAC peptide also moderately accelerated the removal of the methyl groups by LSD2, although the activity of the MT NPAC peptide was lower than that of the WT NPAC peptide (Figure 5, entry 4 vs entry 5 ). The moderate activity of the MT NPAC peptide is due to the deacrease in interaction between the MT peptide and the H3K4 substrate peptide. ${ }^{9}$

We then evaluated PCPA for its LSD2 inhibitory activity using the same assay conditions as those in entry 4 of Figure 5. As shown in Figure 6, PCPA dosedependently decreased the amounts of the demethylated $\mathrm{H} 3 \mathrm{~K} 4$ products (mono- and nonmethylated $\mathrm{H} 3 \mathrm{~K} 4$ peptides), confirming the LSD2 inhibitory activity of PCPA.

\section{WT : $\mathrm{H}_{2} \mathrm{~N}-\mathrm{DPHFHHFLLSQT-OH}$ \\ MT : $\mathrm{H}_{2} \mathrm{~N}-\mathrm{DPHAHHFLLSQT-OH}$}

Figure 3. Wild-type (WT) and mutant (MT) NPAC dodecapeptide (residues 214-225). 

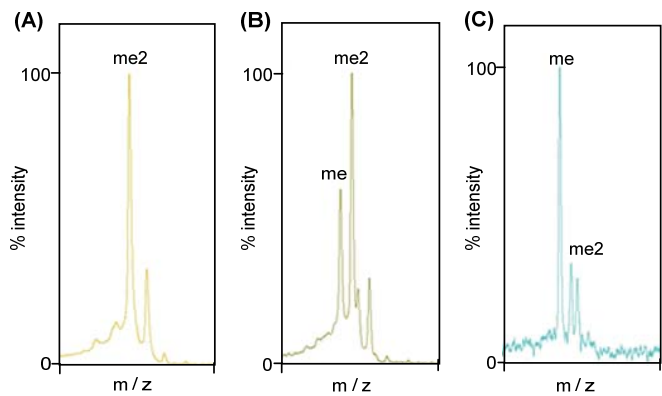

Figure 4. MALDI-TOF MS analysis of H3K4 peptides: (A) $0 \mu \mathrm{g}$ of LSD2 and $0 \mu \mathrm{g}$ of NPAC peptide, (B) $0.5 \mu \mathrm{g}$ of LSD2 and $0 \mu \mathrm{g}$ of NPAC peptide, and (C) $0.5 \mu \mathrm{g}$ of LSD2 and $0.5 \mu \mathrm{g}$ of NPAC peptide.

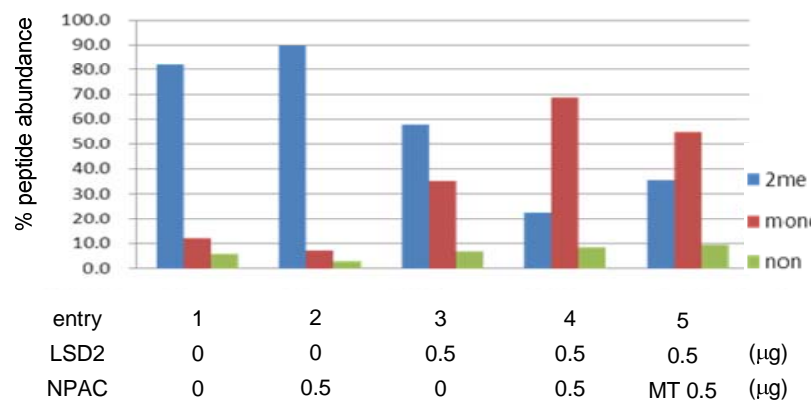

Figure 5. H3K4 demethylation by recombinant LSD2 in the presence or absence of LSD2 and NPAC peptide. Percentages of H3K4me2 peptide (blue), H3K4me1 peptide (red), and nonmethylated $\mathrm{H} 3 \mathrm{~K} 4$ (green) were measured by MALDI-TOF MS analysis. The $\%$ peptide abundance values are means of two separate experiments. The differences in duplicate experiments are within $10 \%$.

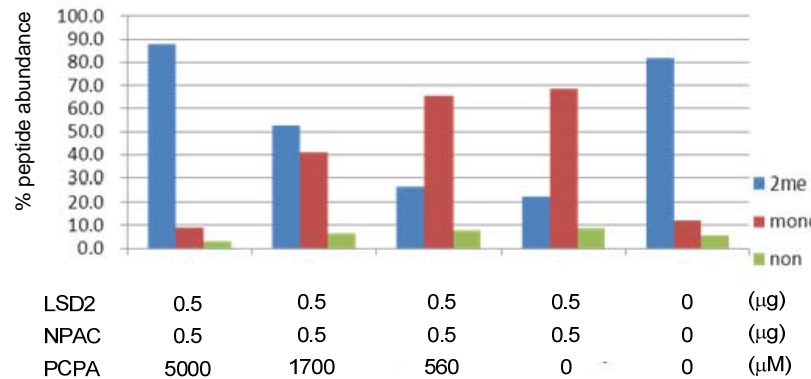

Figure 6. LSD2 inhibition by PCPA. Percentages of H3K4me2 peptide (blue), H3K4me1 peptide (red), and nonmethylated $\mathrm{H} 3 \mathrm{~K} 4$ (green) were measured by MALDI-TOF MS analysis. The $\%$ peptide abundance values are means of two separate experiments. The differences in duplicate experiments are within $10 \%$.

Table 1. LSD2 and LSD1 inhibitory activities of PCPA, NCL1, NCD18, NCD25, NCD33 and NCD41.

\begin{tabular}{ccccc} 
& \multicolumn{2}{c}{$\mathrm{IC}_{50}(\mu \mathrm{M})^{\mathrm{a}}$} & & selectivity \\
\cline { 2 - 3 } compound & $\mathrm{LSD} 2$ & $\mathrm{LSD1}^{\mathrm{b}}$ & & $\mathrm{LSD} \mathrm{IC}_{50} / \mathrm{LSD} 1 \mathrm{IC}_{50}$ \\
\hline PCPA & $2300 \pm 1400$ & $31 \pm 12^{\mathrm{c}}$ & & 74 \\
$\mathrm{NCL1}$ & $26 \pm 10$ & $2.5 \pm 0.5^{\mathrm{d}}$ & & 10 \\
$\mathrm{NCD} 18$ & $60 \pm 18$ & $0.30 \pm 0.13^{\mathrm{c}}$ & 200 \\
$\mathrm{NCD} 25$ & $230 \pm 120$ & $0.48 \pm 0.28^{\mathrm{c}}$ & 480 \\
$\mathrm{NCD} 33$ & $250 \pm 92$ & $0.41 \pm 0.08^{\mathrm{c}}$ & 610 \\
$\mathrm{NCD} 41$ & $>540$ & $0.58 \pm 0.10^{\mathrm{c}}$ & $>930$
\end{tabular}

${ }^{a}$ Values are means of at least three experiments. ${ }^{b}$ LSD1 inhibitory activity was examined using peroxidase-coupled assay (ref 3 and 4$).{ }^{\circ}$ Taken from the literature (ref 5). ${ }^{\mathrm{d}}$ Taken from the literature (ref 3).
Next, using the LSD2 assay system with the NPAC peptide, the LSD2 inhibitory activities of several LSD1 inhibitors, NCL1, NCD18, NCD25, NCD33, and $\mathrm{NCD} 41$ (Figure 1), were evaluated and the $\mathrm{IC}_{50}$ values determined. ${ }^{14}$ As shown in Table 1 , the $\mathrm{IC}_{50}$ value of PCPA was $2300 \pm 1400 \mu \mathrm{M}$ in the LSD2 assay system. LSD1 inhibitors NCL1 and NCD18 inhibited the demethylase activity of LSD2 with $\mathrm{IC}_{50}$ values of $26 \pm$ $10 \mu \mathrm{M}$ and $60 \pm 18 \mu \mathrm{M}$, respectively. $\mathrm{NCD} 25\left(\mathrm{IC}_{50}=\right.$ $230 \pm 120 \mu \mathrm{M})$ and $\mathrm{NCD} 33\left(\mathrm{IC}_{50}=250 \pm 92 \mu \mathrm{M}\right)$ moderately inhibited LSD2. The inhibitory effect of NCD41 $\left(\mathrm{IC}_{50}>540 \mu \mathrm{M}\right)$ was obviously weaker than those of the other inhibitors. These assay results showed that the LSD2-inhibitory activity of NCL1 is greater than that of NCD series of compounds while NCL1 is less active LSD1 inhibitor than NCDs, which leads to high LSD2-selectivity of NCD compounds as compared with NCL1. In addition, the assay data highlighted the significance of the biphenyl group in LSD1-selectivity (Table 1, NCD18 vs NCD25, NCD33 and NCD41). As a result, NCD41 was found to be the most selective inhibitor for LSD1 rather than LSD2. As mentioned above, LSD2 has been reported to inhibit lung cancer cell growth, ${ }^{7}$ and it has been suggested that compounds that selectively inhibit LSD1 over LSD2 may be desirable as anticancer agents. Therefore, the NCD series of compounds, including NCD41, are expected to serve as lead compounds for anticancer agents.

In summary, we developed an LSD2 enzymatic assay system that uses recombinant LSD2 and a synthetic NPAC peptide. In the assay system, an enhancement of the demethylation reaction by LSD2 was observed with the addition of the NPAC peptide by massspectrometry-based analysis. Several LSD1 inhibitors were evaluated using the LSD2 assay system. The LSD1 inhibitors inhibited LSD2 with relatively high $\mathrm{IC}_{50}$ values, showing their high selectivity for LSD1. Further exploratory studies of selective LSD inhibitors using this LSD2 assay with the NPAC peptide are under way.

\section{Acknowledgements}

We thank Professor Takaki Koide and Ms. Mie Tsuchida for technical support. This work was supported in part by a Waseda University Grant for Special Research Projects (T.K.; project number 2015K-191), a Grant-in-Aid for Scientific Research (T.K.; C, 26460159) from MEXT (The Ministry of Education, Culture, Sports, Science and Technology), the Japan Society for the Promotion of Science (T.S.), JST CREST program (T.S.), Takeda Science 
Foundation (T.S.), and the Research Foundation for Pharmaceutical Sciences (T.S.).

\section{References and Notes}

1. Højfeldt, J. W.; Agger K.; Helin, K. Nature Rev. Drug Discov. 2013, 13, 917.

2. Suzuki, T.; Miyata, N. J. Med. Chem. 2011, 54, 8236

3. Ueda, R.; Suzuki, T.; Mino, K.; Tsumoto, H.; Nakagawa, H.; Hasegawa, M.; Sasaki, R.; Mizukami, T.; Miyata N. J. Am. Chem. Soc. 2009, 131, 17536.

4. Ogasawara, D.; Suzuki, T.; Mino, K.; Ueda, R.; Khan, M. N.; Matsubara, T.; Koseki, K.; Hasegawa, M.; Sasaki, R.; Nakagawa, H.; Mizukami, T.; Miyata, N. Bioorg. Med. Chem. 2011, 19, 3702.

5. Ogasawara, D.; Itoh, Y.; Tsumoto, H.; Kakizawa, T.; Mino, K.; Fukuhara, K.; Nakagawa, H.; Hasegawa, M.; Sasaki, R.; Mizukami, T.; Miyata, N.; Suzuki, T. Angew. Chem. Int. Ed. 2013, 52, 8620.

6. Itoh, Y.; Ogasawara, D.; Ota, Y.; Mizukami, T.; Suzuki, T. Comput. Struct. Biotechnol. J. 2014, 9, e201402002.

7. Yang, Y.; Yin, X.; Yang, H.; Xu, Y. Mol. Cell 2015, $58,47$.

8. Recombinant His-tagged human full-length LSD2 was obtained using the following protocol. ${ }^{15}$ The AOF1 gene encoding human LSD2 (amino acids 1-822) was amplified by PCR using cDNA from HeLa cells as template with forward primer 5'CAGTAATCATATGGCAACTCCACGGGGGAGG ACAAAG-3' and reverse primer 5'TAGTCTCGAGTTAAAATGCTGCAATCTTGCTT G-3'. Underlines show restriction enzyme sites for Nde I and Xho I that were introduced into the forward and reverse primers, respectively. The PCR product was ligated into pET28b (Novagen Inc., Madison, WI) and digested with Nde I and Xho I, and the resultant plasmid was designated pETLSD2. Escherichia coli BL21 (DE3) cells were transformed with pETLSD2 for the expression of full-length LSD2 bearing a hexahistidine tag at the N-terminus. Recombinant $E$. coli BL21 (DE3) cells carrying pETLSD2 were grown in $200 \mathrm{~mL}$ of NZCYM medium containing $50 \mu \mathrm{g} / \mathrm{mL}$ kanamycin at $37{ }^{\circ} \mathrm{C}$ with shaking at $200 \mathrm{rpm}$. When the absorbance at $600 \mathrm{~nm}$ reached 0.7 , the temperature was lowered to $16{ }^{\circ} \mathrm{C}$ and isopropyl- $\beta$-Dthiogalactopyranoside was added to make a final concentration of $0.5 \mathrm{mM}$. The culture was continued for a further $19 \mathrm{~h}$ with shaking at $110 \mathrm{rpm}$, and the cells were harvested by centrifugation at $3,100 \times g$ for 10 min at $4{ }^{\circ} \mathrm{C}$. LSD2 was purified by chromatography through a HisTrap column. The partially purified LSD2 was dissolved in $50 \mathrm{mM}$ HEPES-NaOH $(\mathrm{pH}$ 8.0) containing 5\% glycerol, 1 $\mathrm{mM}$ PMSF, $1.5 \mu \mathrm{g} / \mathrm{mL}$ pepstatin A, and $1.5 \mu \mathrm{g} / \mathrm{mL}$ leupeptin, and stored at $-30{ }^{\circ} \mathrm{C}$ until use.

9. Fang, R.; Chen, F.; Dong, Z.; Hu, D.; Barbera, A. J.; Clark, E. A.; Fang, J.; Yang, Y.; Mei, P.; Rutenberg,
M.; Li, Z.; Zhang, Y.; Xu, Y.; Yang, H.; Wang, P.; Simon, M. D.; Zhou, Q.; Li, J.; Marynick, M. P.; Li, X.; Lu, H.; Kaiser, U. B.; Kingston, R. E.; Xu, Y.; Shi, Y. G. Mol. Cell 2013, 49, 558.

10. Chen, F.; Yang, H.; Dong, Z.; Fang, J.; Wang, P.; Zhu, T.; Gong, W.; Fang, R.; Shi, Y. G.; Li, Z.; Xu, Y. Cell Res. 2013, 23, 306.

11. Fields, G. B; Noble, R. L. Int. J. Peptide Protein Res. 1990, 35, 161.

12. NPAC dodecapeptides (WT: $\mathrm{H}_{2} \mathrm{~N}$-DPHFHHFLLSQT$\mathrm{OH}, \mathrm{MT}: \mathrm{H}_{2} \mathrm{~N}$-DPHAHHFLLSQT-OH were prepared by conventional solid-phase peptide synthesis using Fmoc strategy. The synthetic peptides were purified by reverse-phase HPLC and lyophilized to give white powders. The peptides were analyzed by matrixassisted laser desorption ionization time-of-flight mass spectrometry (MALDI-TOF MS) using Bruker autoflex with $\alpha$-cyano-4-hydroxycinnamic acid (CHCA) as the matrix. WT peptide, MALDI-TOF MS calcd. for $\mathrm{C}_{69} \mathrm{H}_{96} \mathrm{~N}_{19} \mathrm{O}_{18}[\mathrm{M}+\mathrm{H}]^{+} 1479.6420$, obsd. 1479.857. MT peptide, MALDI-TOF MS calcd. for $\mathrm{C}_{63} \mathrm{H}_{92} \mathrm{~N}_{19} \mathrm{O}_{18} \quad[\mathrm{M}+\mathrm{H}]^{+}$1403.5440, obsd. 1403.347, respectively.

13. The histone demethylation reaction for assaying LSD2 activity was carried out for $1 \mathrm{~h}$ at $37^{\circ} \mathrm{C}$ in $20 \mu \mathrm{L}$ of 50 $\mathrm{mM}$ HEPES-NaOH (pH 8.5) containing 0.1\% BSA and $10 \mu \mathrm{M} H 3 \mathrm{~K} 4 \mathrm{me} 2$ peptide (chemically synthesized peptide consisting of the first 21 amino acid residues of histone H3, incorporating dimethylated lysine at position 4; Sigma-Aldrich) in the absence or presence of 0.5 $\mu \mathrm{g}$ of His-tagged full-length LSD2 and $0.5 \mu \mathrm{g}$ of NPAC peptides. The reaction was stopped by adding $20 \mu \mathrm{L}$ of matrix solution $(5 \mathrm{mg} / \mathrm{mL}$ CHCA, $37 \%$ acetonitrile, and $0.12 \%$ trifluoroacetic acid), and then sonicated for $30 \mathrm{sec}$. One $\mu \mathrm{L}$ of the reaction mixture was spotted on the sample plate, dried, and analyzed by MALDI-TOF MS using JMS-S3000 (JEOL).

14. $\mathrm{IC}_{50}$ evaluation assays of LSD2 were carried out in 20 $\mu \mathrm{L}$ of buffered solution incubated for $1 \mathrm{~h}$ at $37{ }^{\circ} \mathrm{C}$ with $10 \mu \mathrm{M} \mathrm{H} 3 \mathrm{~K} 4 \mathrm{me} 2$ substrate peptide, $1 \mu \mathrm{g}$ of LSD2, $1 \mu \mathrm{g}$ of NPAC peptide (WT), and inhibitors at several concentrations. Mass-spectrometry-based analysis was carried out using the above-mentioned method to evaluate the demethylation activity of LSD2. $\mathrm{IC}_{50}$ values are means \pm S.D. of at least three experiments; PCPA $=2300 \pm 1400 \mu \mathrm{M}, \mathrm{NCL} 1=26 \pm$ $10 \mu \mathrm{M}, \mathrm{NCD} 18=60 \pm 18 \mu \mathrm{M}, \mathrm{NCD} 25=230 \pm 120$ $\mu \mathrm{M}, \mathrm{NCD} 33=250 \pm 92 \mu \mathrm{M}, \mathrm{NCD} 41>540 \mu \mathrm{M}$.

15. Mino, K.; Nishimura, S.; Ninomiya, S.; Tujii, H.; Matsumori, Y.; Tsuchida, M.; Hosoi, M.; Koseki, K.; Wada, S.; Hasegawa, M.; Sasaki, R.; MurakamiYamaguchi, Y.; Narita, H.; Suzuki, T.; Miyata, N.; Mizukami, T. Biosci. Biotechnol. Biochem. 2014, 78, 1010 . 